\title{
INFORMATION TECHNOLOGY MODEL FOR PRODUCT LIFECYCLE ENGINEERING
}

\author{
Bhanumathi KS, B Haridas \\ National Civil Aircraft Development, CSIR-National Aerospace Laboratories \\ Old Airport Road, Kodihalli, Bangalore 560017,India \\ (Bhanumathi, hari) @nal.res.in
}

\begin{abstract}
An aircraft is a complex, multi-disciplinary, system-engineered product that requires real-time global technical collaboration through its life-cycle. Engineering data and processes which form the backbone of the aircraft should be under strict Configuration Control (CC). It should be model-based and allow for 3D visualization and manipulation. This requires accurate, realtime collaboration and concurrent engineering-based business processes operating in an Integrated Digital Environment (IDE). The IDE uses lightweight, neutral Computer Aided Design (CAD) Digital Mock-Up (DMU). The DMU deals with complex structural assemblies and systems of more than a hundred thousand parts created by engineers across the globe, each using diverse CAD, Computer Aided Engineering (CAE), Computer Aided Manufacturing (CAM), Computer Integrated Manufacturing (CIM), Enterprise Resource Planning (ERP), Supply Chain Management(SCM),Customer Relationship Management(CRM) and Computer Aided Maintenance Management System (CAMMS) systems. In this paper, a comprehensive approach to making such an environment a reality is presented.
\end{abstract}

\section{KEYWORDS}

PLM, IDE, CC, DMU, MBD, CAMMS, collaborative design.

\section{INTRODUCTION}

The Confederation of Indian Industry (CII) report, names India as one of the fastest-growing civil aircraft markets in the world. India's air passenger travel has been growing at almost 25 percent a year. Trade estimates indicate that India may need 900 civil transport planes in the next 20 years worth about 73 billion US dollars [1]. India has certain level of qualified manpower, knowledge base skills, facilities in the areas of $R \& D$ and engineering of aircraft, manufacturing and servicing systems, which needs to be enhanced. This opportunity beckons the industry to create a more comprehensive, vibrant, high speed, modern engineering ecosystem, comprising design (concept, structures, and systems), manufacturing engineering, tool engineering, operations engineering, servicing engineering, quality and reliability engineering capabilities. One of the requirements of such an eco system is Information Technology (IT) infrastructure for collaboration. To start with, information required for defining the specifications of an aircraft, would comprise indicators of economic growth, societal and cultural changes, meteorological data and air-traffic data - product definition surveys technology forecasts etc. While some of this information is available through IT infrastructure maintained as sub-systems by government and private agencies, no single integrated IT infrastructure exists to date. This integrated IT infrastructure data would require intelligence built in by way of analytical ability through software, to carry out a variety of

Jan Zizka (Eds) : CCSIT, SIPP, AISC, PDCTA - 2013

pp. 459-475, 2013. (C) CS \& IT-CSCP 2013

DOI : $10.5121 /$ csit.2013.3652 
analysis including trend analysis and extrapolation. Hence there is need for handling engineering processes from concept to retirement.

\section{A. Characteristics of Information Technology Infrastructure}

Presently, a hybrid system of engineering transactions (manual and computerized) exists. With this system, a typical achieved concept to commercialization time is 15 to 20 years. By the time the aircraft is commercialized it will become obsolete in life cycle performance due to advances in technology. It is necessary to build an information technology infrastructure as a network enabling innovation, reduce time to market and re-engineering through concurrency and collaborative actions between myriad R \& D and engineering agencies, instead of the past successive actions in vertically integrated set ups, which were resulting in excessive reengineering, effort and cost. In the aircraft industry, lack of effective communication between the functions of design, manufacturing and assembly causes delays and setbacks whereby production capabilities are unable to realize design intent in high-complexity product models [2].It has also been established that an information technology infrastructure provides a safe-net against challenges arising from continuous innovations, global collaborations and at the same time, making product and process data accessible to everyone [3]. Such an information technology infrastructure is provided by an open PLM business/engineering process. information technology infrastructure requires the following characteristics:

1. Open PLM based and configuration controlled Engineering processes for life cycle (Concept to Retirement)

2. An IDE. All engineers work on 3D models, MBD of Parts, light weight CAD neutral DMU of Virtually assembled Aircraft only.

3. DMU based engineering works on the basis of neutral CAD light weight visualization and manipulation software. Thus, all disciplines are concurrently working on a virtual aircraft platform seamlessly, regardless of the pedigree of the application software they use and high level of innovation/Optioneering is possible.

4. Achieving $100 \% \mathrm{MBD}$ of objects and assemblies of the product.

5. Digital Manufacturing Software (DMS) tools used through PLM for virtual/dynamic process design, design for manufacturing, its simulation, tool design, factory design in context and validation.

6. Enable System Engineering Technique in system design (mechanical/electrical /avionic /engine)

7. Produceability and Maintainability are built into the design and simulation in the early part of the product life cycle (Before Prototype), namely Design For Manufacturing Analysis (DFMA) and Design For reliability and Maintenance (DFRAM)

8. Virtual -Prototype, build sequencing simulation, testing and validation

9. Virtual Piece part Manufacture, tool and plant development by Design in 3D in context.

10. Virtual Reality (VR) validation of the product design, manufacturing, modification, and servicing.

11. Highest interoperability between $\mathrm{CAD} / \mathrm{CAE} / \mathrm{CAM} / \mathrm{CIM} /$ software to be facilitated based on industry accepted standards and SOA - PLM standards evolution on Industry accepted basis with flexibility, interoperability for life cycle to handle heterogeneous, proprietary and emerging software tools

12. Online /Real Time engineering collaboration, through Web in different Modes (immersed or synchronous or asynchronous) AND /OR

13. Online /Real Time engineering collaboration, through Cloud Computing using Software as a Service (SaaS), Platform as a Service (PaaS) and Infrastructure as a Service (IaaS) 


\section{INTEGRATED DIGITAL ENVIRONMENT}

\section{A. Necessity}

The engineering methods of Indian aircraft industry are in a stage of transition from manual, 2D engineering drawings, manual analysis, text-based product /process and servicing information to 3D Models in MBD and digital engineering processes. It is now feasible to model, visualize and simulate the dynamic functions of product and process in virtual reality and innovate the designs to meet all market requirements early in the design cycle and also finalize the tool design for any rate of manufacture. However it is recognized that to stem the competition and survive in business [4]. It is necessary to absorb results of continuing $R \& D$, innovate to create new concepts and engineer them for creating better products, improving product quality, reducing product cost and time-to-market. This requires an IDE based PLM. An IDE provides hardware, software, visualization infrastructure/platform to all the engineering players in an Aircraft program throughout its life, to carry out their innovation functions through CAD, CAE, CIM and CAM SW and have the execution carried out by ERP Systems duly interfaced. In creating such a system CAx tools (Computer Aided, where x stay for Design, Styling, Manufacturing, Engineering, Process Planning, etc.), PLM tools, and smart technologies like cloud computing have revolutionized modeling techniques, virtual prototyping, digital mock up and created intelligent factory networks that encourage effective collaboration [5],[6]. However, the great variety of proprietariness and differences in software makes integration difficult and hinders seamless engineering activity between the heterogamous software tools. It calls for expensive adhoc interface software and their development effort and time. Hence in creating an IDE in a PLM, interoperability through industry accepted standard becomes essential and work in this area is urgently required in the Indian context. An IDE in PLM uses hardware, software with high interoperability, a light weight CAD neutral format providing high accuracy visualization and manipulation platform to all engineers. Engineers at various sites will work and innovate by DMU based engineering under $\mathrm{CC}$ for product and process. Among the various new techniques possible with a PLM, the ability to carry out DFMA and DFMRO using DMS software VR based simulation, validation, Geometric Dimensioning and Tolerance (GD\&T) will obviously create effective design. This minimizes errors at the design stage which can adversely impact the schedule, performance, quality and cost. In short, all the stages of the life cycle are simulated in VR and aircraft is preassembled on computer [7].

Aircraft industry in India is 70 years in age. The technique of IDE on a PLM system is not yet adopted and the industry is paying heavily for this by not able to absorb quickly the improvements feasible by the advancing technologies. Concurrent Engineering does not exist. The Indian scenario is marred by poor traceability of engineering data during production and maintenance of the aircraft, the authors speak from their own experience. 'Successive' processes of design/manufacturing/maintenance have taken a much longer than scheduled time to market, Therefore, it becomes imperative to incorporate an IDE into our program. An IDE open PLM allows visualization of the product /process to all throughout its life cycle, facilitating innovation concurrent design and collaboration. All Engineers can see partial assemblies as the components are designed by different members of the team globally. Assembly analysis tests are carried out for some components intersecting on assembly (Design error), kinematic simulation of the functioning of the product and testing of dynamic stresses and finite element analysis. With IDE, DMU Based Engineering, CAD/CAM/CAE/CIM, the design stage itself allows for all improvements their simulation and validation. The fields covered for enveloping by an IDE are given in Figure 1 [8]. 


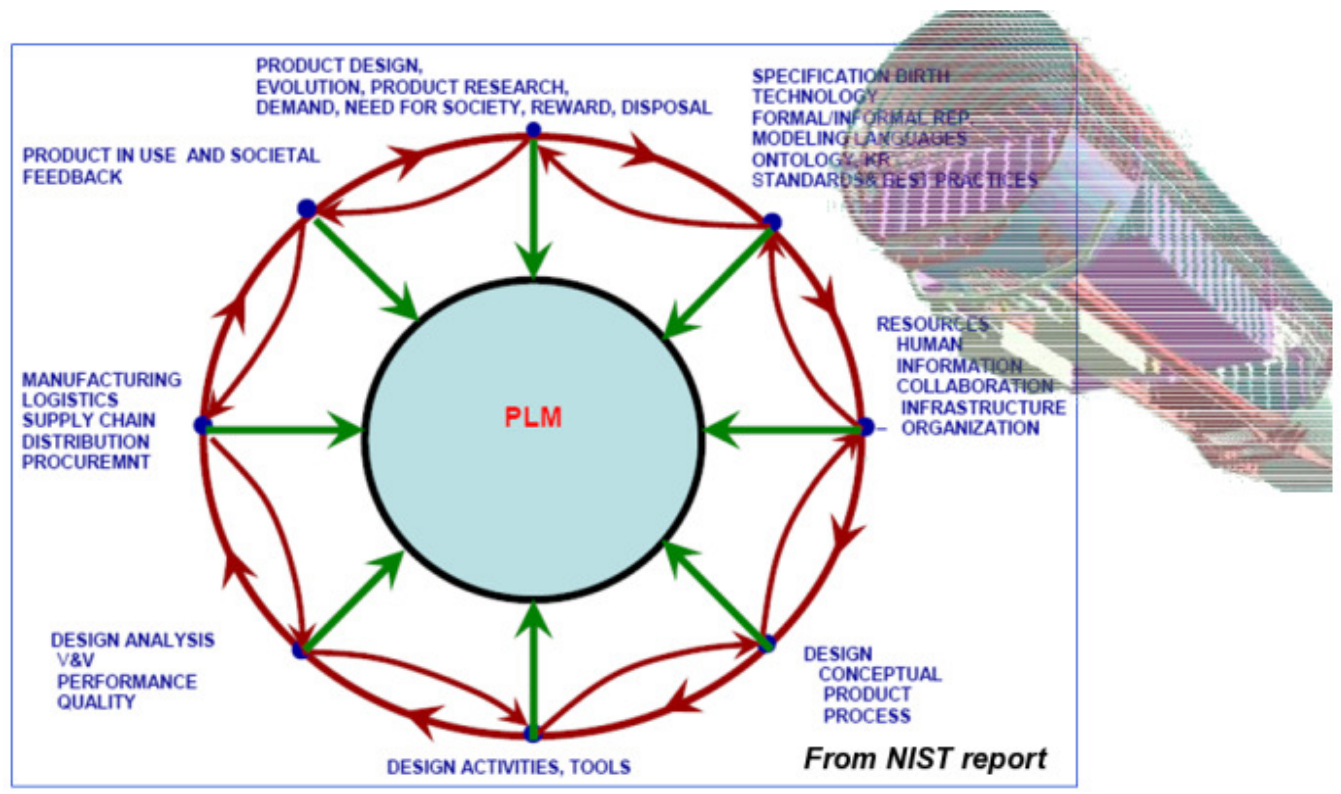

Fig. 1 Fields covered for enveloping by an IDE through PLM

\section{B. Importance of PLM standards, Interoperability and SOA for IDE}

Infrastructure wise, the life of the elements vary widely with respect to time depending on dynamics of their development. This leads to recurring seamlessness and related interruptions in interface software. Figure 2 illustrates the age wise complexity across the life span of elements [9]. Sustained seamlessness in the system calls for open interoperability standards to be complied in their software design and related hardware compatibilities by the OEMs involved. One such industry accepted standards is ISO 10303, with several protocols for CC, MBD, exchange of data generated in different CAD software, product modelling standard for collaboration and interoperability. However for compressed transmission and also for neutrality with respect to $\mathrm{CAD}$, and for MBD containing geometrics and Product Manufacturing Information (PMI), light weight CAD Neutral software was required, especially for collaborative design in heterogeneous system environment, and such tools are now coming up. Typically, the set of standards recommended by the National Institute of Standards and Technology (NIST) in consultation with a large number of industry users of PLM software are:

- ISO 10303, STandard for the Exchange of Product (STEP), suite of standards used to exchange product model data.

- American National Standards Institute ANSI (Government Electronics \& Information Technology)/Association GEIA-927 (Government Electronics\& Information Technology Association), Common data schema for complex systems, is an integrated multi domain data schema for representing product and process data.

- EIA (Electronic Industries Alliance)-836, Configuration management and data exchange and interoperability, provides a means to create a central source of configuration management information for exchange among necessary partners.

- ANSI/EIA-649, National consensus standard for configuration management, describes configuration management functions and principles and defines a neutral terminology 
As the STEP standards of translators do not reduce the volume, there is further improvement with the advent of the light weight CAD Neutral format for DMU and MBD where the compressions of the order of 10/15 to 1 are reported ISO Publically Available Specification(PAS) 14306 for one of the open formats / the light weight formats and AP 214 suitable for MBD and DMU for collaborative engineering. The initial use of ISO 10303, informally known as STEP model data has brought proven cost savings. Further benefits have been realized by the introduction of light weight neutral CAD formats and MBD [10]. In Figure 3 NIST showcase use of the manner in which standards in PLM, greatly reduces the number of interfaces required is because each system will only require an import and export translator from the internal data format of the commercial system to the standard data model.

For an effective IDE, the lifecycle collaborative engineering spectrum demands, integrating data from other software, and presenting the right information in the right context anywhere on any device. Service-oriented architecture (SOA), introduced in an attempt to allow for breakdown and re-assembly of business models and processes into services, built on layers of open standards and is capable of handling changes through each of the stages and across the life span of the elements. It is a well-defined, self-contained 'service' function that does not depend on the context or state of other services. It plays a crucial role in dealing with the challenge of a heterogeneous environment containing integrated systems, making sure that work flows with flexibility and robustness. Promotes re-use of components, reduces development and deployment costs [11].

\section{The span for the IDE infrastructure in PLM system}

The span of digital data exchanges in the life of an aircraft comprises of several states of the product structure of an aircraft to be defined as X BOM where X represents the states such as given under the AS xx conditions depicted in Figure 4[12]. Under each state the various types of technical information to be handled is listed, The Information loop connecting Design /manufacture/operation and maintenance including the process for change as executed in an IDE based PLM are indicated.

\section{Configuration Management (CM) through PLM system}

According to EAI-649A standards, CM is defined as "A process that establishes and maintains consistency of a product's attributes with its requirements and product configuration information throughout the product's life cycle". This will apply to Product and Process.

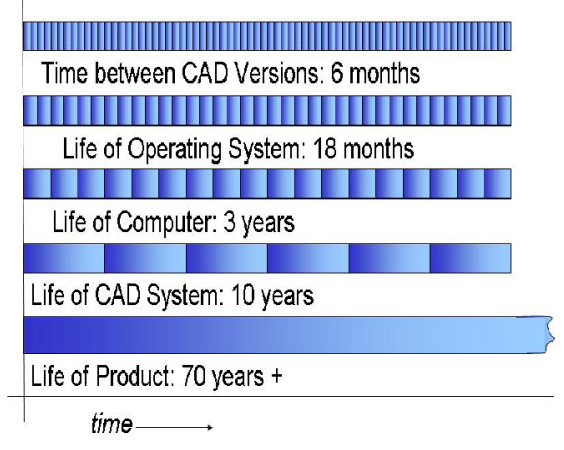

Fig. 2 Varying Life span of elements

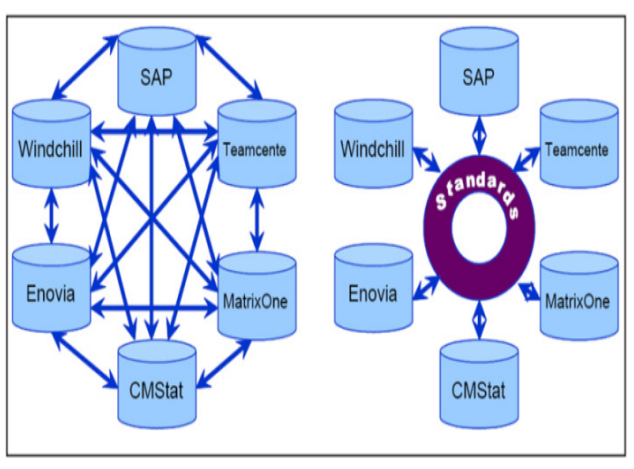

Figure 3 how standards tackle interoperability 
Such control is exercised in a PLM infrastructure by Unique Tail Number based hierarchal Numbering Systems called Bill Of Materials (e-BOM) is assigned to the applicable Aircraft in a top-down sequence as the design evolves from the Aerodynamic profile into the parts of the aircraft, following the sequence of final assembly, major assembly, major sub-assembly, sub assembly and to piece parts. During the various stages in development, manufacture and use, there are bound to be changes and as such the configuration is controlled in several progressive AS -XXXX conditions as in Fig 4. Concurrently, the parts are represented in the CAD neutral light weight DMU visible to all engineers. PLM software will ensure a single file for all documentation defining the Aircraft and its parts controlled against the part number.

\section{E. Model Based Definition}

In engineering, 2D drawings are being progressively replaced by 3D models at piece part level and at assembly levels. It is necessary to ensure that all GD\&T and PMI (earlier being conveyed through 2D drawings - Geometry, tolerances, Limits, fits, finish, Material, Special Processes, Instruction etc) be conveyed through the MODEL itself. Engineering drawings are subjected to a document lifecycle which includes data preservation, storage, destruction, security and transportation. They represent intellectual property, and are valued as evidence and as legal information [13]. For the MBD file to eventually as equivalent to 2D engineering drawings, MBD datasets, will have to contain all information. Software and hardware enabling capabilities would also be required [14]. A single part file called Model Based Definition (MBD) for each part number, is required which will contain ALL of the DATA.. Using MBD files and DMU, the PLM SW and infrastructure will allow editing and manipulation of CAD/CAE/CAM/CIM data created in any heterogeneous system, including revisioning, check-in/check-out, attributes, synchronization, automatically and bilaterally between native CAD and the Lightweight DMU etc. There are one or two PLM OEM light weight CAD Neutral SW tools that support MBD.PLM-centric automation and lends itself to parallel and distributed processing [15].

Infrastructure of such intelligent nature appears to already exist in aircraft industry. For example the Boeing B-777is reported to be one of the first in the aircraft industry to boast of a $100 \%$ digital definition. Digital data were used to drive the manufacturing processes whenever possible. The entire aircraft assembly was simulated using digital techniques[16].With the advent of light weight CAD format in which the software can been stored and tweaked as and when required, a single file MBD will provide all information governed by the light weight CAD neutral DMU and CC. This will enable collaboration and contribute to innovation across the product lifecycle. Example of MBD file is presented in Figure 5. 


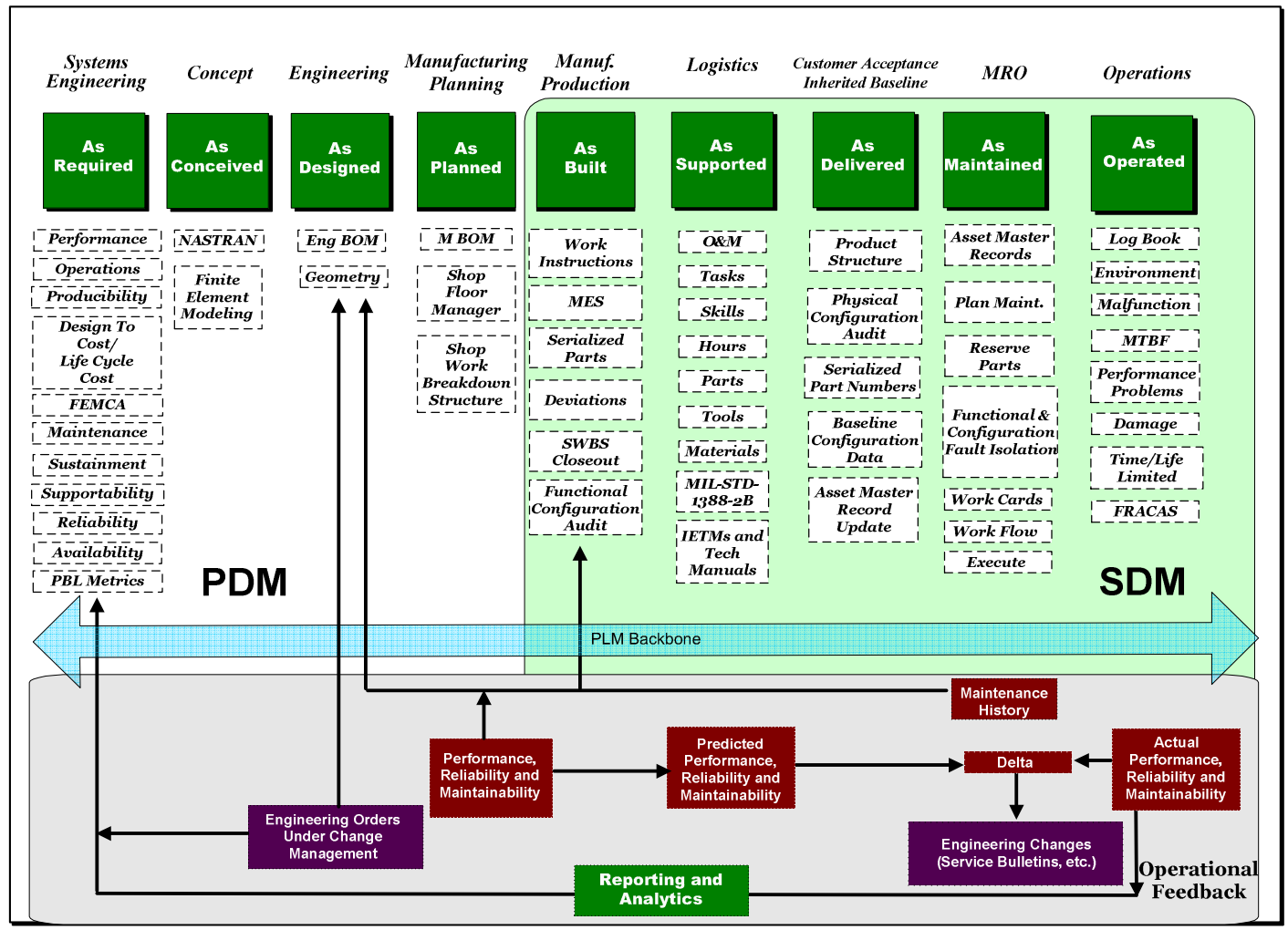

Fig. 4 End to End Engineering Activity MAP of an Aircraft PLM

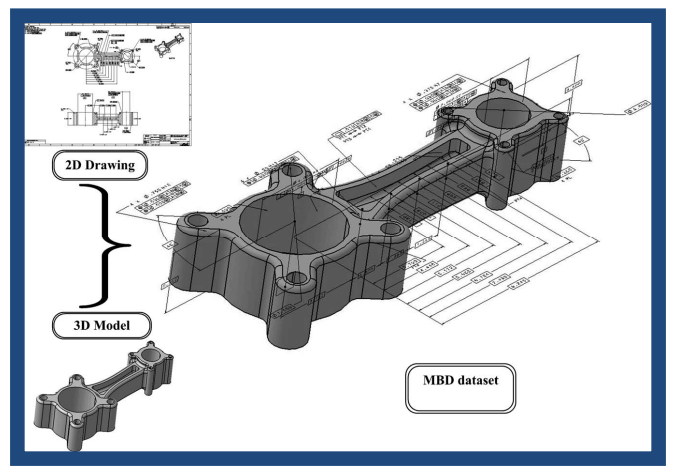

Fig. 5 Example of an MBD dataset

\section{F. Digital Mock Up Unit - DMU (in Light Weight CAD Neutral Format)}

The Digital Mock up of an aircraft created under CC using CAD neutral format replaces the old method of using costly Physical Mock Up[17]. The DMU is evolving as a virtual aircraft as the design is realized in a top down manner from concept, through preliminary design, detail design. The availability of the DMU especially in CAD neutral format of light nature enables, concurrent engineering based collaboration between various design groups of the aircraft regardless of their physical location or the type of CAD / CAE / CAM software they may be using. Clash/ tolerance/ interference/ variance analysis along with assembly path planning is made possible in concurrent mode leading to parallel processing and optimal layouts. Further it aids the functions of design for manufacturing and design for Reliability Availability Maintainability (RAM) to be 
built in early in the design life. DMU makes all of the above possible. Parts and the product structure continually populate the DMU, evolving the e BOM. The lightweight format should be capable of seamless absorption of data from heterogeneous CAD/CAE systems[18].The lightweight CAD neutral DMU visualization process in PLM software allows visualising a particular configuration or a product structure for all use processes under strict $\mathrm{CC}$ and change management control vital in aircraft design/ manufacture/ support procedures. It allows non$\mathrm{CAD}$ users to gain access to the 3D model with an ease of use and without any training, for purposes of incorporation in documentation, promotional literature training. The lightweight DMU visualization also allows visualising a particular configuration or a product structure for al use processes under strict Configuration control and Change management control vital in aircraft design procedures. It allows non-CAD users to gain access to the $3 \mathrm{D}$ model with an ease of use and without any training, for purposes of incorporation in documentation, promotional literature training.[18]. There are one or two PLM OEM light weight, neutral CAD and high level MBD compliant PLM software that support DMU based engineering. The role of DMU in Life cycle is mapped in Figure 6.

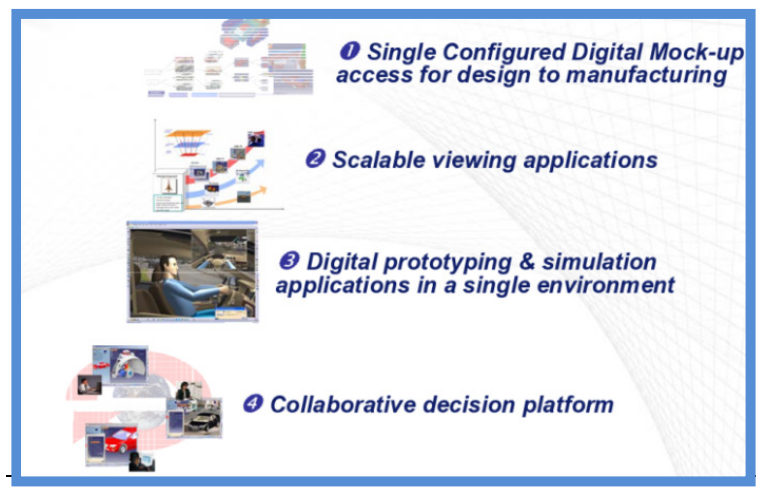

Fig. 6 Use of DMU in concept to certification cycle

The Design for Assembly and maintainability simulations are depicted in figure 7 on the light weight CAD neutral DMU.
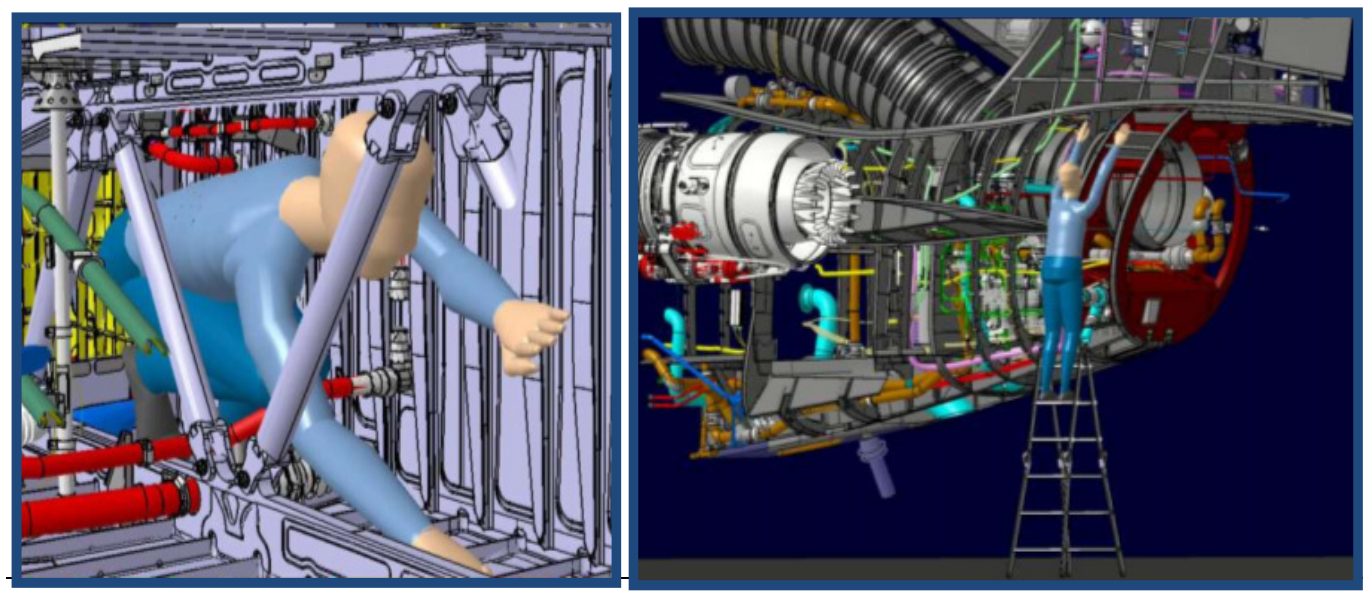

Fig. 7 Design for Maintainability and Digital Simulation in an IDE 


\section{G. Collaborative Design and design in context using CAD neutral light weight DMU in PLM}

Using collaborative engineering, the collocated team is replaced with an interactive team structure where, even though the team members are geographically distributed and the best engineering talent can come together to bolster the design effort[19]. There are one or two PLM OEM tools that support concurrent/collaborative engineering using light weight CAD neutral format, other PLM OEMs are also working towards this. Presented below are the results and extracts from the proof of concept exercise carried out with a PLM OEM to demonstrate the light weight neutral CAD DMU based design process, from the start of aircraft design through collaborative engineering between aircraft structural design group and electrical design group[20]. In these proof of concept cases the native CAD used for structure was CAD Type 1, DMU was in Type A CAD neutral light weight format. The schematics in CAD Type 2 and the Pipe and Wire 3D routing-Layout in CAD Type 3 but automatically represented in Type A CAD Neutral lightweight format in the DMU, all of which showing the excellent interoperability feasible using the Type A CAD Neutral lightweight format. The Reverse Directionality of the system was also confirmed.

Step 1 Start of Design

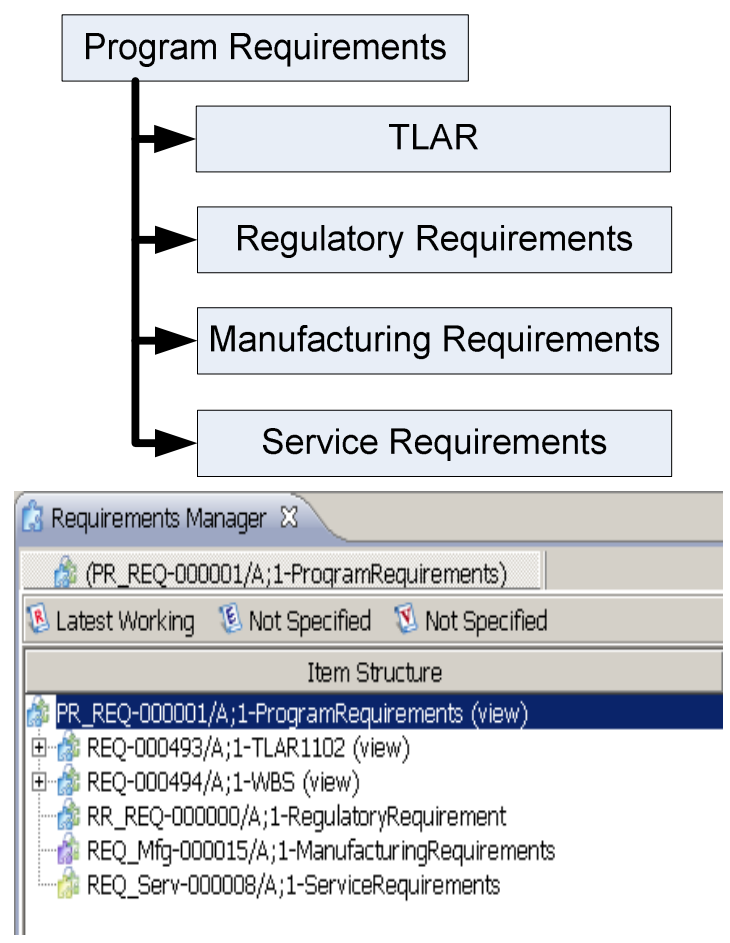

Fig 8 Screen shots of Requirement-BOM in PLM, with Top level requirement, work break down structure, Regulatory, Manufacturing and Service Requirements

Step 2 Configuration Controlled Top level Design schemes and Top level DMU 

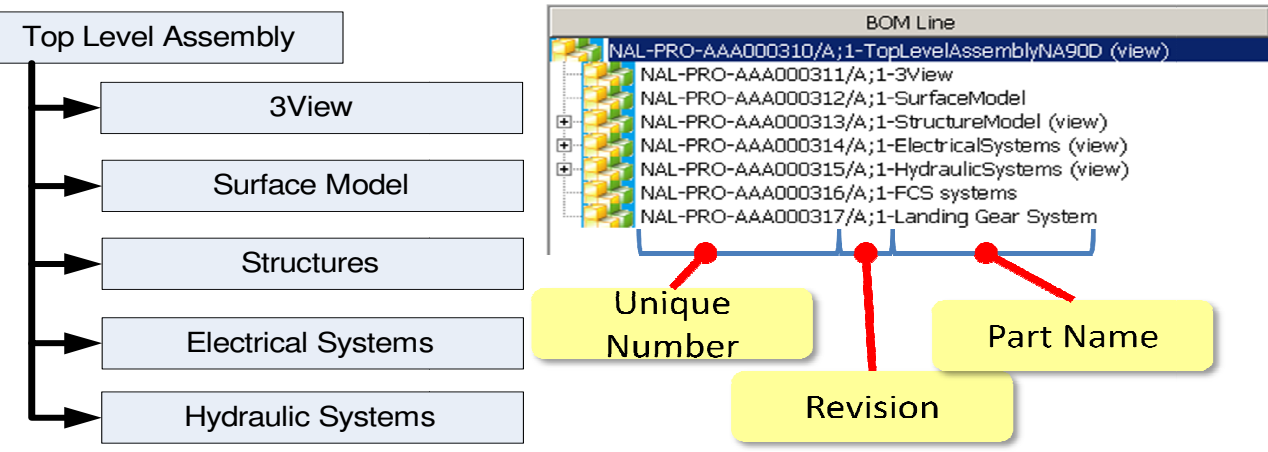

Fig. 9 PLM screen shot of product structure definitions with numbering system

\section{Step 3 Derivation of Collaboration capable DMU of Structure}

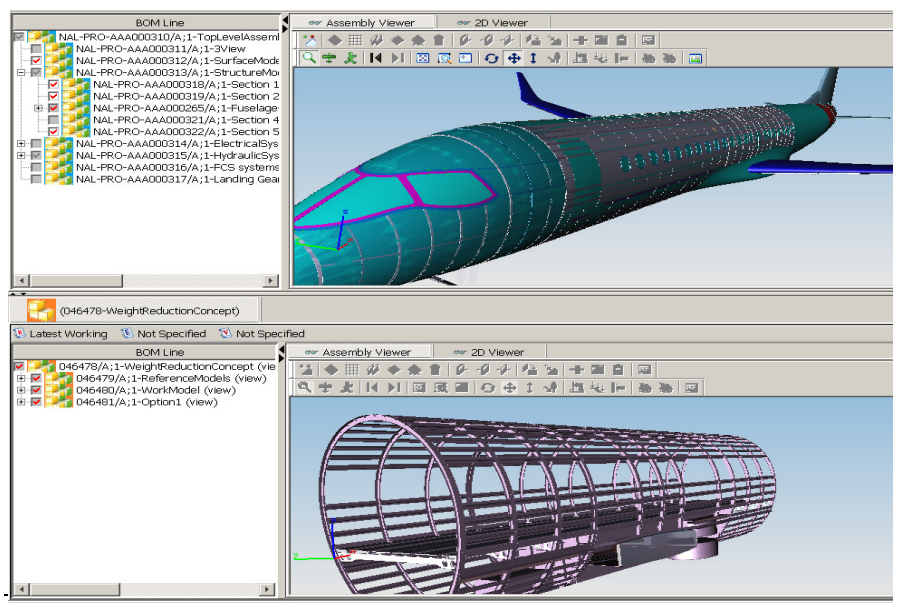

Fig. 11 PLM screen shot showing the derivation of Structure DMU in lightweight CAD neutral with e $\mathrm{BOM}$

Step 4 Steps of Collaborated Design in Context of Electrical Installation DFM/DFMRO/release

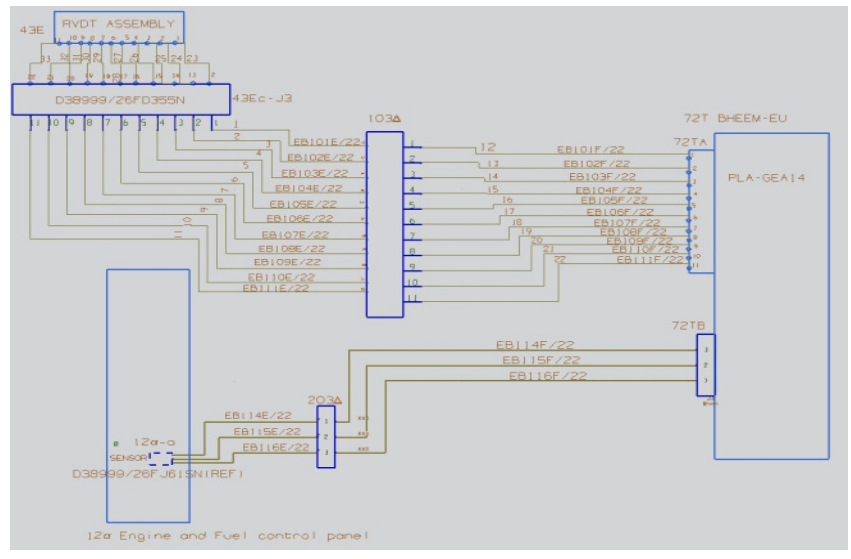

Fig. 12 Wiring Schematic Logical data in any CAD 


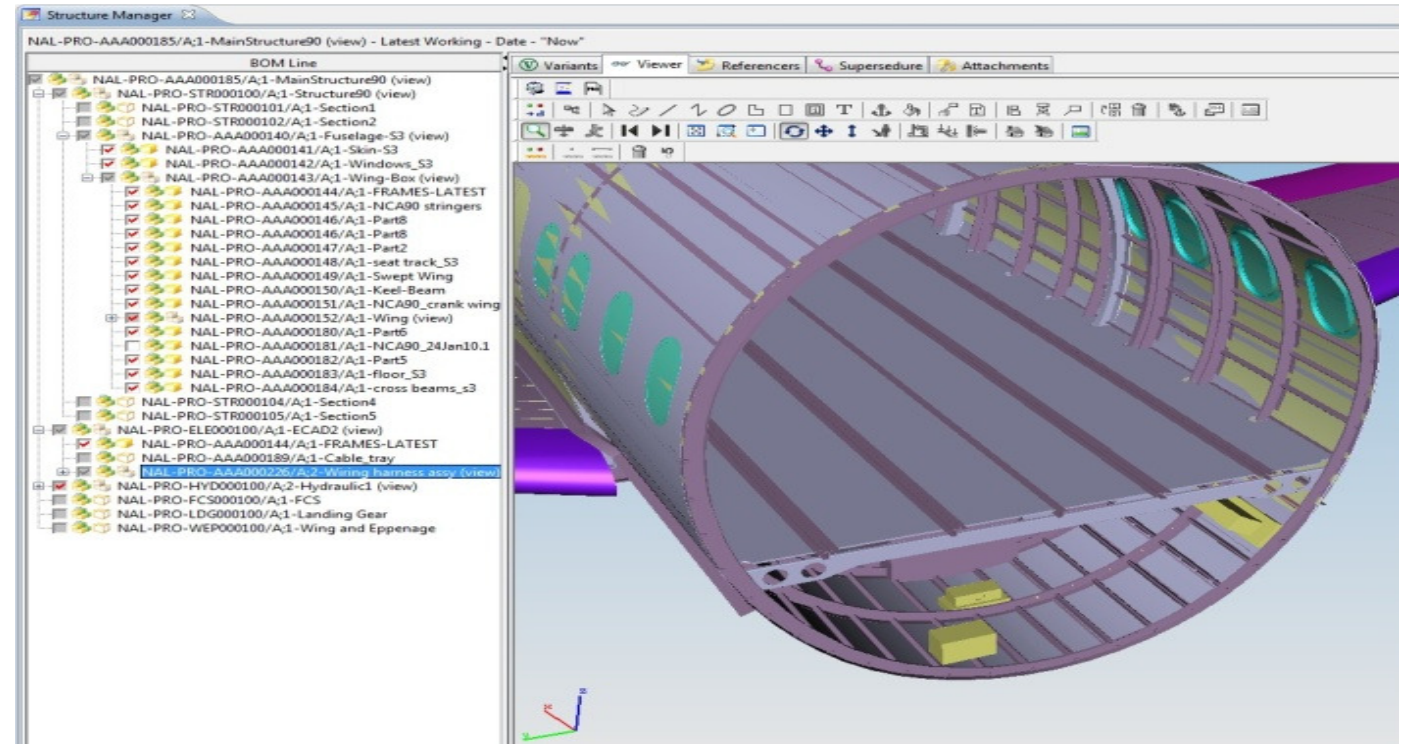

Fig. 13 DMU Devices are located in the DMU and synched with the Schematics layout

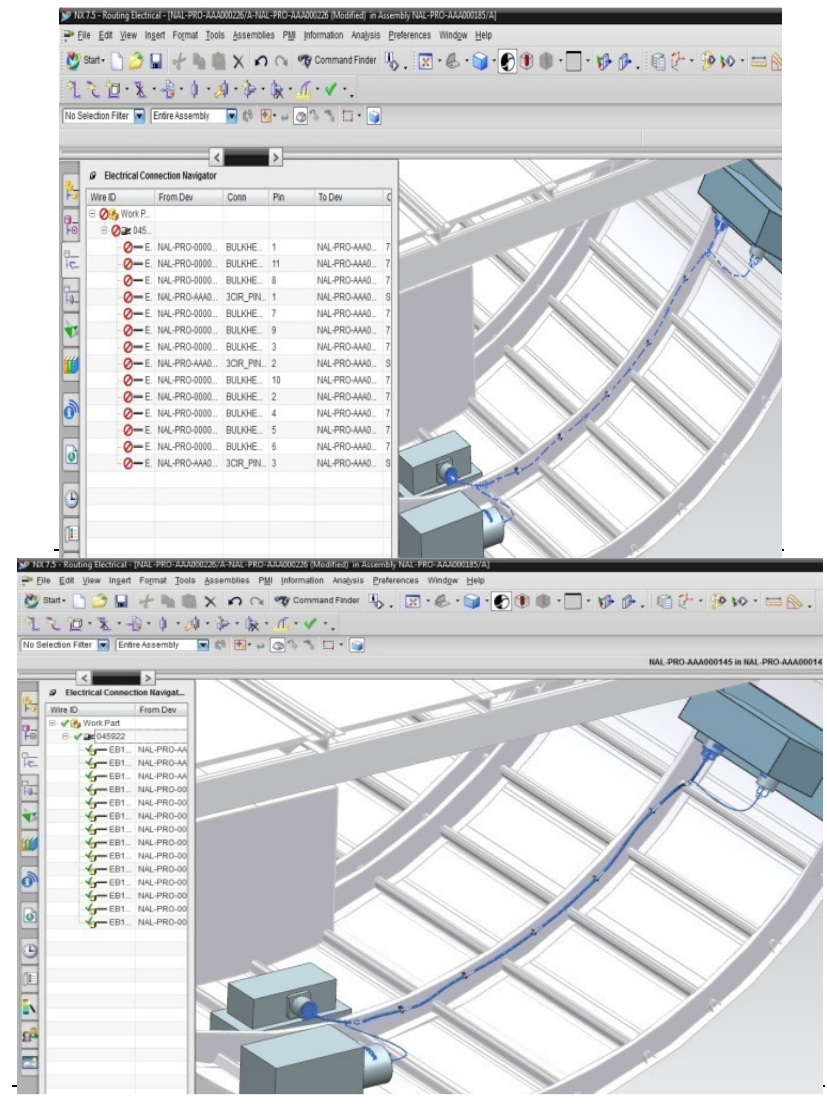

Fig 14 Creation of Centreline Routing

Fig. 16 Routing between connections along centerline 


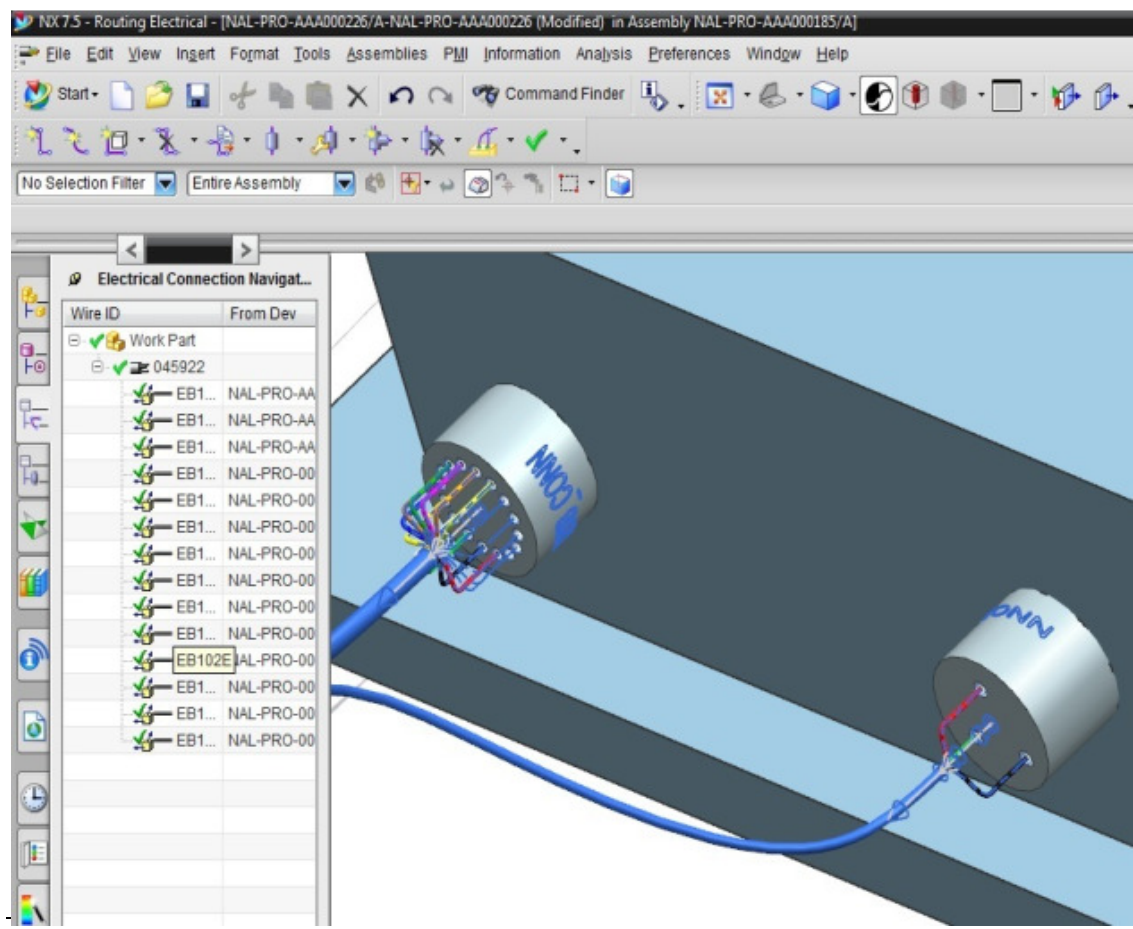

Fig. 17 Auto Routing at Pin Level

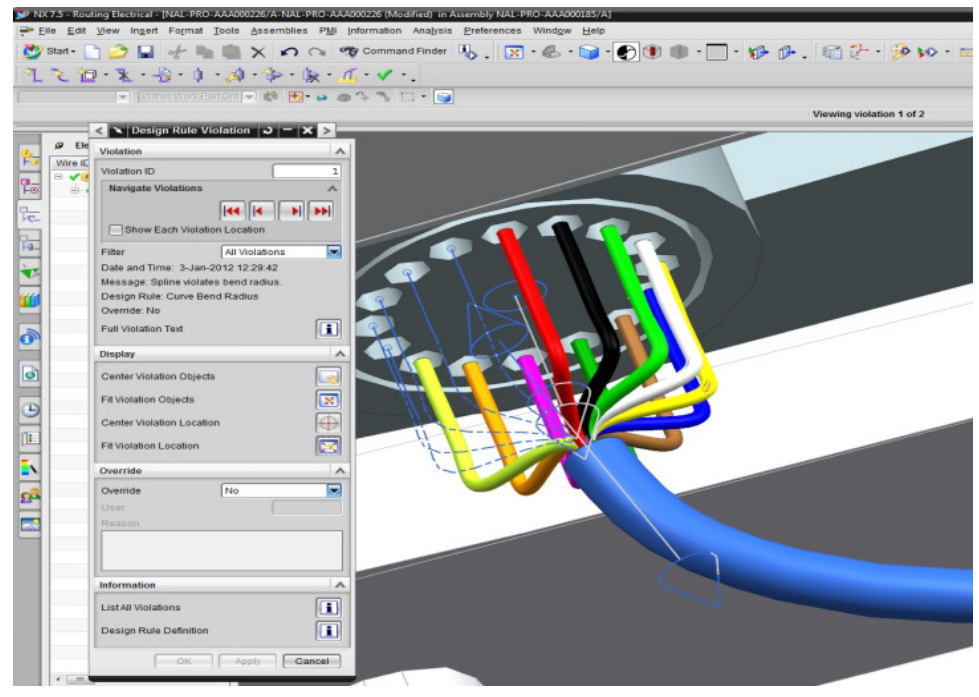

Fig. 18 Validation of Design rule ( radius etc)

Step 5 Collaborative engineering on Light weight CAD Neutral DMU in respect of a Hydraulic system is demonstrated below 


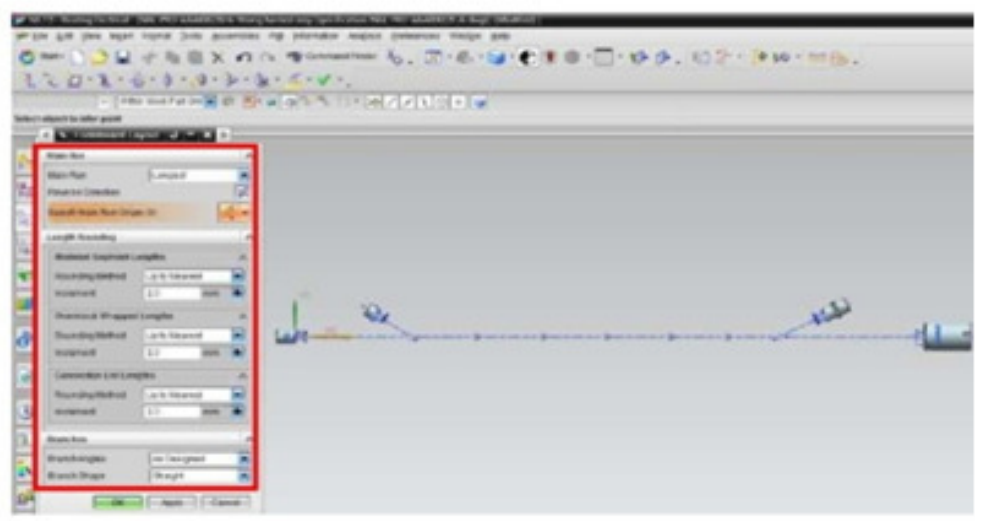

Fig. 19 Screen shots of Automatic Formboard creation and different options for layout

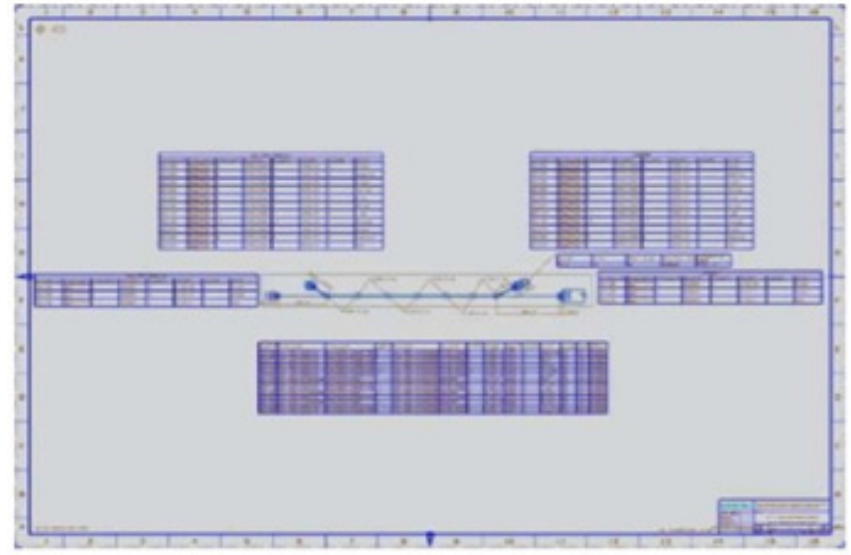

Fig. 20 Screen shots of Automatic Formboard drawing with connection list, pin list, Length of wire, mass properties etc.

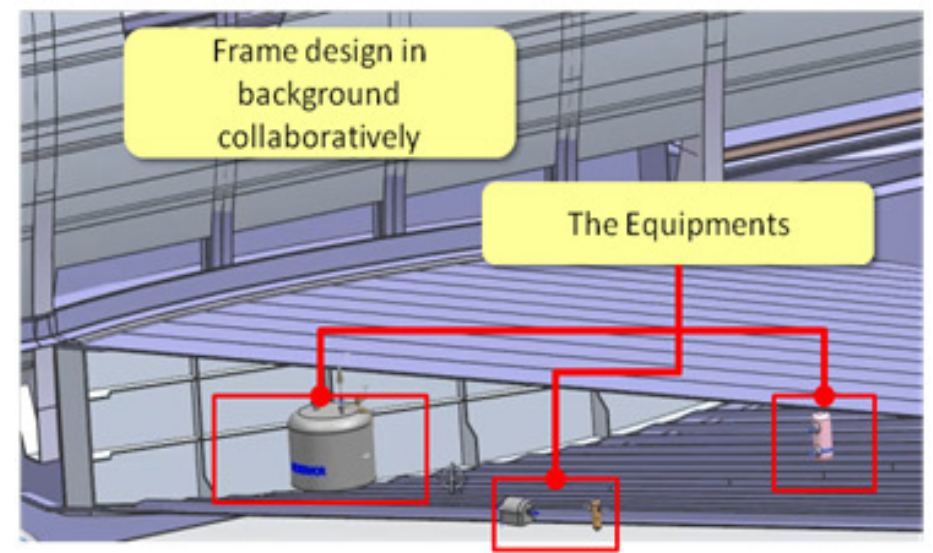

Fig. 21 Screen shots of equipments in Context of Assembly, in this case frame design(CAD Type 1) is being collaboratively performed by Structures 


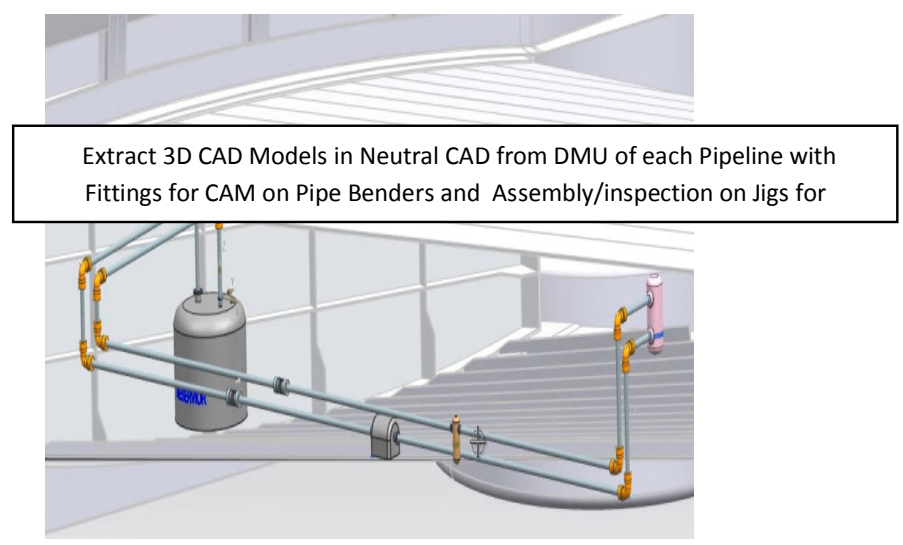

Fig. 22 Screen shots of Piping done interactively between equipments

\section{H. Infrastructure for Collaboration}

Baseline requirements comprise an Open PLM collaborative system software and process working on a light weight CAD neutral system, MBD and system engineering PLM software under CC networking all the engineers as needed globally is the need. 'Design Anywhere, Manufacture Anywhere (DAMA)' is a mantra that has emerged over the recent years[21]. Web based interlinks and Cloud computing will play a critical role in the realization of DAMA. Cloud computing adoptions are of two types in the manufacturing sector, manufacturing with direct adoption of some cloud computing technologies and cloud manufacturing, the manufacturing version of cloud computing[22]. The promise of cloud computing is to deliver all the functionality of existing information technology services and reducing the upfront costs of computing that deter many organizations from deploying many cutting-edge IT services[23]. The impetus for adopting cloud computing right now is seen predominantly from a costs perspective, even though, the promises from a technological functionality perspective are equally beneficially[24].The configuration depends on the resources and computing systems available with the Aircraft Prime and the Collaborator. Several configurations are feasible as given below.

1) Simple WAN based Engineering Collaboration Transaction System: This system should operate in the following modes of status of equipment of the Design Prime (NCAD) and the Collaborators, as depicted in Table 1.

2) CLOUD computing based Collaboration Transaction System: The PLM system/processes should be capable of operation in collaborative mode on a secure Aircraft Prime Cloud as needed, with defined and acceptable security, The Cloud method should allow the services shown in Table 2.

In today's networked economy, strategic business partnerships and outsourcing has become the dominant paradigm where companies focus on core competencies and skills, as creative design, manufacturing, or selling[25].In the Indian context, most of the sub contracted engineering work requires Small and Medium Enterprise (SME) (Tier 3) level participants /partners by the aircraft prime. The SMEs or Universities, or Free lance specialists will not have the necessary techno economics to invest in high end infrastructure as they may not have enough orders to ensure maximum utilization and recover the investments. In such case, the CLOUD method and related infrastructure appears to be the right win-win investment decision. In the case of Tier 1 and 2 Participants who could be firms with diversified and large businesses having enough 
infrastructure or PLM and ERP or having investment capability thereon, the Wide Area Network(WAN) method would work effectively.

Table 1 Simple WAN Based Engineering Collaboration Transaction System

\begin{tabular}{|l|l|}
\hline Mode 1 & $\begin{array}{l}\text { Collaborator works inside the Aircraft Prime PLM, IP and Processes controlled by } \\
\text { Aircraft Prime PLM }\end{array}$ \\
\hline Mode 2 & $\begin{array}{l}\text { Collaborator works in own PLM environment, with own teams and local business } \\
\text { processes, Automatic synchronization and mapping with the Aircraft Prime PLM }\end{array}$ \\
\hline Mode 3 & $\begin{array}{l}\text { Collaborator works in own environment, but has links permitted under security } \\
\text { protocol of Aircraft Prime to retrieve context data and updates, Coordinated } \\
\text { processes, monitoring by Aircraft Prime PLM }\end{array}$ \\
\hline Mode 4 & $\begin{array}{l}\text { Collaborator works in own environment, and does not have access to the Aircraft } \\
\text { Prime PLM, NCAD's PLM is responsible to provide data and manage the } \\
\text { interaction,Coordinated processes, monitoring by Aircraft Prime PLM }\end{array}$ \\
\hline
\end{tabular}

Table 2 Cloud Computing Based Collaboration Transaction System

\begin{tabular}{|l|l|}
\hline SaaS & $\begin{array}{l}\text { Aircraft Prime licenses an application to collaborator in design for use as a } \\
\text { service on-demand and online }\end{array}$ \\
\hline (PaaS) & $\begin{array}{l}\text { Aircraft Prime will deliver computing platform and solution stack as a } \\
\text { service }\end{array}$ \\
\hline (IaaS) & $\begin{array}{l}\text { Aircraft Prime will deliver computer infrastructure (typically a platform } \\
\text { virtualization environment) as a service }\end{array}$ \\
\hline $\begin{array}{l}\mathrm{S}+\mathrm{S} \\
\text { Software } \\
\text { plus } \\
\text { Services }\end{array}$ & $\begin{array}{l}\text { Aircraft Prime will operate a Hybrid model, with some components in the } \\
\text { cloud', others on the device for Higher flexibility, and regulated } \\
\text { connectivity on- need -only basis }\end{array}$ \\
\hline $\begin{array}{l}\text { Vital } \\
\text { condition }\end{array}$ & $\begin{array}{l}\text { Most Importantly the CLOUD system should ensure 100\% accurate transfer } \\
\text { of all Geometric, line, surface Colour information (ALL DMU and MBD } \\
\text { information) with reliable security }\end{array}$ \\
\hline
\end{tabular}

\section{CONCLUSIONS}

As can be seen from the information presented, from the benefits accruable, to engineering industry(Aircraft) such as (a) low time from concept to market, (b) speedy execution of continuous improvement programme and (3) more effective maintenance all by implementation of an IDE/PLM as information technology the following can be taken up immediately by industry / government for implementation.

1. Information Technology with IDE is an urgent requirement in India for rapid growth of the aeronautical industry.

2. Standards for interoperability of diverse Software should be created in India on an industry accepted basis.

3. DMU based engineering under Configuration Control through PLM and efficient CAD neutral light format has to be standardised.

4. Infrastructure for the above including use of model based definition must be created.

5. Collaboration through cloud computing has to be implemented.

6. The life cycle engineering processes using IDE, DMU, MBD and PLM should be standardised by regulative authorities in their design/engineering procedure

7. All R\& D organisations, manufacturing engineering groups, should be networked by appropriate IDE/PLM 


\section{ACKNOWLEDGMENT}

Our sincere thanks to Mr. Shyam Chetty, Director, CSIR-NAL for conducting this study, Dr. Sathish Chandra, Project Director-NCAD and HOD STTD-NAL for guidance.

\section{REFERENCES}

[1]. 'Changing Dynamics -Indian Aerospace Industry, Confederation of Indian Industry CII report,2009.

[2] 14A. Whiteside, E. Shehab,",Developing a Current Capability Design for Manufacture Framework in the Aerospace Industr", Proc. of the $19^{\text {th }}$ CIRP Design Conference-Competitive Design, Cranfield University,30-31 March 2009,pp223.

[3] S.G. Lee a,Y.-S. Maa, G.L. Thimm a, J. Verstraeten b, "Product lifecycle management in aviation maintenance,repair and overhaul", Computers in Industry 59 (2008) 296-303.

[4] D. Van Wijk, B. Eynard, N. Troussier, F. Belkadi, L. Roucoules, G. Ducellier,"Integrated Design and PLM Applications in Aeronautics Product Development", Proc. of the 19th CIRP Design Conference - Competitive Design, Cranfield University, 30-31 March 2009, pp128].

[5] Sergio Terzi,Marco Taisch,"Collaborative product development at a global scale: the role of PLM IT solutions",http://www.amicommunities.eu/pub/bscw.cgi/d494329/66_Terzi_and_Taisch_on_PLM.pdf

[6] Xun $\mathrm{Xu}$, "From cloud computing to cloud manufacturing" Robotics and Computer-Integrated Manufacturing, 28 (2012) 75-86.

[7] S. Parekh, R. Roy and P. Baguley, "Design and Manufacturing Uncertainties in Cost Estimating within the Bid Process:Results from an Industry Survey", Proc. of the $19^{\text {th }}$ CIRP Design ConferenceCompetitive Design,Cranfield University,30-31 March 2009,pp1788].

[8] Jean-Yves Delaunay, Thomas Drehmel,"European ebusiness standard is at iogoverance",http://www.asdssg.org,accssed 22nd Aug. 2012.

[9] Aerospace Industry Guidelines for Implementing Interoperability Standards for Engineering Data Version 1.0 , February 12, 2009, Engineering Data Interoperability Working Group, Aerospace Industries Association of America, Inc. http://www.aiaaerospace.org/assets/aerospace_interoperability_standards_021209.pdf

[10] Sudarsan Rachuri, Sebti Foufou, Sharon Kemmerer, "Analysis of Standards for Lifecycle Management of Systems for US Army --- a preliminary investigation" NISTIR 7339,National Institute of Standards and Technology , technology administration , August 2006

[11] Enrico Vezzetti ,"Product lifecycle data sharing and visualisation: Web-based approaches", Int J Adv Manuf Technol (2009) 41:613-630.

[12] www.siemens.com/plm.

[13] R.Pedauque,"Document:Form, Sign and Medium, as Reformulated for Electronic Documents",2003, http://archivesic.ccsd.cnrs.fr/docs/00/06/22/28/PDF/sic_00000594.pdf

[14] Virgilio Quintana a, Louis Rivest a, Robert Pellerin b, Fre'de' rick Venne a, Fawzi Kheddouci a, "Will Model-based Definition replace engineering drawings throughout the product lifecycle? A global perspective from aerospace industry". Computers in Industry 61 (2010) 497-508

[15] Jonathan G. Lund, Nathanie L. Fife and C. Gregory Jensen3,"PLM-Based Parametrics for Design Automation and Optimization", Computer-Aided Design \& Applications, Vol. 2, Nos. 1-4, 2005, pp 37-45 12

[16] K.J. Sharma, B. Bowonder, "The making of Boeing 777: a case study in concurrent engineering", International Journal of Manufacturing Technology and Management,6 (3-4) (2004) 254-264.

[17] [R. Stark, F.-L. Krause , C. Kind, U. Rothenburg, P. Müller, H. Stöckert," Competing in Engineering Design - the Role of Virtual Product Creation", Proc. of the $19^{\text {th }}$ CIRP Design ConferenceCompetitive Design, Cranfield University,30-31 March 2009,pp1

[18] E. Shehab, M. Bouin-Portet, R. Hole, C. Fowler, "Enhancement of Digital Design Data Availability in the Aerospace Industry",.Proc. of the $19^{\text {th }}$ CIRP Design Conference-Competitive Design, Cranfield University,30-31 March 2009,pp589.

[19] D. Van Wijk, B. Eynard, N. Troussier, F. Belkadi, L. Roucoules, G. Ducellier,"Integrated Design and PLM Applications in Aeronautics Product Development", Proc. of the 19th CIRP Design Conference - Competitive Design, Cranfield University, 30-31 March 2009, pp128 . 
[20] Bhanumathi K S, B.Haridas, "Familiarization of PLM (design domain only),(through test cases)", NCAD internal report, 19th Jun.2012

[21] Heinrichs W. "Do it anywhere". IEE Electronics Systems and Software 2005;3(4):30-3.

[22] Xun Xu, "From cloud computing to cloud manufacturing, Robotics and Computer"-Integrated Manufacturing 28 (2012) 75-86], ]

[23] J. Staten, "Hollow Out The MOOSE: Reducing Cost With Strategic Right sourcing", Forrester Research, Inc., 2009.

[24] Sean Marston a, Zhi Li a, Subhajyoti Bandyopadhyay a, Juheng Zhang a, Anand Ghalsasi, "Cloud computing — The business perspective", Decision Support Systems 51 (2011) 176-189.

[25] [C. Agostinho, B. Almeida, M.J. Nuñez-Ariño, R. Jardim-Gonçalves, "Interoperability and Standards: The Way for Innovative Design in Networked Working Environments", Proc. of the $19^{\text {th }}$ CIRP Design Conference-Competitive Design, Cranfield University,30-31 March 2009,pp139 